\title{
Systematic Mapping of Digital Gap and Gender, Age, Ethnicity, or Disability
}

\author{
Inés Alvarez-Icaza Longoria ${ }^{1, * \mathbb{C}}$, Rogelio Bustamante-Bello ${ }^{2} \mathbb{(}$, María Soledad Ramírez-Montoya ${ }^{3}(\mathbb{D}$ and \\ Arturo Molina 2 (D) \\ 1 School of Architecture, Art and Design, Tecnologico de Monterrey, Mexico City 14380, Mexico \\ 2 School of Engineering and Science, Tecnologico de Monterrey, Mexico City 14380, Mexico; \\ rbustama@tec.mx (R.B.-B.); armolina@tec.mx (A.M.) \\ 3 School of Humanities and Education, Tecnologico de Monterrey, Monterrey 64849, Mexico; solramirez@tec.mx \\ * Correspondence: i.alvarezicaza@tec.mx
}

check for updates

Citation: Alvarez-Icaza L., I.;

Bustamante-Bello, R.;

Ramírez-Montoya, M.S.; Molina, A. Systematic Mapping of Digital Gap and Gender, Age, Ethnicity, or Disability. Sustainability 2022, 14 , 1297. https://doi.org/10.3390/ su14031297

Academic Editor: Jesús-Nicasio

García-Sánchez

Received: 21 December 2021

Accepted: 19 January 2022

Published: 24 January 2022

Publisher's Note: MDPI stays neutral with regard to jurisdictional claims in published maps and institutional affiliations.

Copyright: () 2022 by the authors Licensee MDPI, Basel, Switzerland. This article is an open access article distributed under the terms and conditions of the Creative Commons Attribution (CC BY) license (https:// creativecommons.org/licenses/by/ $4.0 /)$.

\begin{abstract}
Rapid technological evolution defines the first two decades of the millennium. This phenomenon has increased the digital gap, disparities, and inequalities in global and local contexts. This paper reports a systematic literature mapping of 180 articles published from 2000 to 2021 discussing the digital gap. The documents were retrieved using boolean operations in two databases, adding terms related to gender, age, ethnicity, and disabilities, focusing on population groups that are especially vulnerable to the effects of this phenomenon. The method included categorizing the retrieved documents to provide a general view of the most concerning topics in the academic and research community. This analysis concludes (a) the approaches to address this topic are diverse, as this is a multilayered, complex, and interconnected issue; (b) many studies refer to developed countries; however, fewer are those who observe or analyze the underdeveloped regions; (c) the majority of published papers in the last decade report information and communication technologies (ICT) and their role in bridging the gap, showing an opportunity area for designing these technologies considering more accessible approaches through flexible technology approaches; (d) this study's results are a valuable source of information to identify the design requirements for accessible products and service systems. The last section provides a detailed explanation of the findings.
\end{abstract}

Keywords: digital gap; flexible technology; accessible design; educational innovation; higher education; complex thinking

\section{Introduction}

This paper offers an overview of studies regarding the increasing breach between those who have full access to technology and those who do not-understanding that equal access to information and communication technologies (ICTs) and the available resources and skills to receive their benefits is crucial for sustainable changes. During the last 20 years, many scholars and researchers have identified its causes, consequences, and ubiquity in time, space, context, and correlation with other divisions and inequalities, such as poverty, illiteracy, lack of skills, age, gender, ubiquity, etc. The World Economic Forum defines digital gaps as "the differential ability to access data and digital technologies" [1]. It correlates closely to inequalities in the availability and access to technology, and it varies depending on the economic development and cultural dimensions of the world's regions [2]. In April 2021, the UN Deputy Secretary-General, Amina Mohammed, addressed the General Assembly with an important statement: the digital gap is "the new face of inequality" [3]. This inequality does have two sides of a coin: the cause and the effect.

The term "digital gap" is observed in this research as the cause of the unavailability of equipment and lack of skills to effectively use ICTs. More than $87 \%$ of the population in high-income countries have access to the internet, compared to less than $17 \%$ in low-income 
nations. That considerable difference brings other types of gaps; for instance, in 2019, the United Arab Emirates reported more than 200 mobile cellular subscriptions for every 100 people, a 2:1 rate. On the other hand, Latin America and the Caribbean (excluding high-income persons) reported 98 per every 100 people [4]. The disconnection between the benefits of connectivity and its availability cause severe limitations in people who find themselves far from the possibility of understanding how to use technology in their favour. Despite that, as some researchers point out, even when people might have a computer or online connection at reach, it is not safe to assume that this condition implies the skills or capacity to use those tools and resources [5].

The digital divide phenomenon, then, is the consequence of such breach; the World Economic Forum explains this occurs "where the impact ICT has on one's life is influenced by 'soft' inequalities rather than physical access alone" [6]. The division is evidence of the lack of opportunities and access to services, information, and life quality. This paper is mapping documents founded using the term "digital gap" to refer only to the group of causes and, therefore, it is not considering the term "digital divide" that is viewed as a consequence. Studying people who do not have access to ICTs in combination with regions lacking resources and infrastructure such as broadband service, offers a closer look at what has been studied and written on alternatives to increase availability and accessibility for an effective ICT use.

Because of the COVID-19 pandemic, this issue has garnered even more attention in the media and the academic field [7]. However, it is not a new matter; researchers and activists have been diagnosing this problem and urging companies and governments to take action. Sustainable Development Goal 4 aims to "ensure inclusive and equitable quality education and promote lifelong learning opportunities for all." Target 4.5 focuses on eliminating disparities in education and ensuring equal access to vulnerable groups, including persons with disabilities, indigenous peoples, women, and those who "require particular attention" [8].

Even though governments have committed to reaching equal access to education (by adopting the 2030 Agenda for Sustainable Development [9] in 2015), there is an existing sociocultural breach that has a significant impact on the current state of the educational context in the less developed regions of the world [10] (p. 132). The reality for some communities is an urgent need to build and integrate the conditions to bring training, development, jobs, health services, and distance learning closer to people [11] (p. 459). According to some researchers, the primary task should be social integration by providing infrastructure-from broadband access to electronic devices- to increase their possibilities of reaching better jobs, therefore, an improved life quality [12] (p. 22).

When analyzing the digital gap and the digital divide, some researchers point out that it is essential "to look into the analyzed process from the individual perspective (e.g., the biographical background of persons who do not use ICT) and consider the factors present in certain regions, countries or education systems and cultures." [13] (p. 1). Because of their opportunities, educational context, and acceptance or proximity to technological devices, the groups who lack opportunities to use technology to improve their livelihoods [14] include senior citizens, people with disabilities, indigenous groups (first nations), and women. Indeed, other conditions such as immigration and poverty might also affect the reach to ICTs; although, those are often linked to some of the previously mentioned groups.

The 2020 GSMA Report [15], which reported a survey of women and men in 23 lowand middle-income countries across Asia, Africa, and Latin America, showed that women were $10 \%$ less likely to own a mobile phone than men. Additionally, the survey found that women were $26 \%$ less likely to use mobile internet than men. It means that at least 1.2 million women are not using the internet regularly.

Both accessibility (having the ICTs and equipment at reach), and availability (having the infrastructure and service capability that allows ICTs to function correctly), are causing this gap to increase as time passes and technology evolves. Along these lines, Vial [16] did a review within an inductive framework and concluded that organizations would 
need "to implement responses to gain or maintain their competitive advantage." However, in a 2019 study in the Netherlands, a country where $98 \%$ of the population has at-home internet access, the authors found that even there the impact of "age, gender, majority status, employment, education level, and household composition" [17] (p. 3069) contributed to a digital divide. In addition, lack of internet availability and disadvantaged geographic location [18] increase the gap for vulnerable groups. Thus, as the study concludes, an in-depth understanding of how companies adapt designs and strategies to face changes and challenges is urgent.

Sustainability is another relevant consideration for inclusive policies and strategies regarding the digital gap. Many authors and activists warn about focusing only on profit and revenues. Others have agreed that digitalization promotes sustainable economies $[19,20]$. Moreover, beyond inclusion per se are the reflections and notions that will lead to sustainability [21] through policy and decision-making. For many years the digital gap appeared to be a problem only in developing countries [22]. Now we know that this problem affects an increasing number of people and regional development. Consequently, public policies are shifting [23] from a centralized perspective to one focused on access and integration.

To reach such levels of integration between capabilities and resources, academic researchers, decision-makers, company directors, and policy vigilantes must ensure the right combination of facilitating, promoting, and fostering ways to make ICTs accessible for people. Besides policies, actions, and initiatives created to promote digital inclusion, there are also opportunities to take advantage of the existing efforts in technology research and development, whose results may help evolve together as an equal society and observe the needs of individuals [24]. To become change agents, ICT innovators and developers should provide effective use of technologies, aligning it with inclusion strategies and scenarios created in which ICTs can be used in skills acquisition for vulnerable groups [25] (p. 2). Ensuring that people (that so far have been ignored in the connectivity development plans) are not overlooked in the immediate future might bring opportunities. Improving some new technologies faster, such as artificial intelligence, machine learning, terahertz communications, 3D augmented reality, virtual reality, and haptics, to name a few [26], could be a consequence of integrating new features.

As part of ongoing research that focuses on understanding how technology, products, and services (with the capabilities for being intelligent, sensing, responsive, etc.) can help bridge the gap, this paper shows as a significant finding that there are two forms of addressing the digital gap issue. On the one hand, most of the retrieved studies discuss a digital divide diagnosis in a region, culture, or social group; the emphasis is in describing the effect, consequences and, in some cases, the recommendations to take action. On the other hand, the minority of papers discuss the level of technology acceptance, presenting an issue of ICTs that has been proven in a context and reporting how it worked among a group of people. These two descriptions observe and analyze the adaptability of people to existing technologies. Just a few studies offer alternatives to understand better and use those technologies conceived to be accessible and inclusive.

It might be due to standardization purposes-which has been the shared priority for the last years in industry [27] - technological devices are designed for a false majority, which is the typical technology users. That is a possible reason why a few documents were founded describing accessible and inclusive technologies in this mapping. However, today's tools and perspectives (autonomy, machine learning, big data, IoT, etc. [28-30]) allow us to change our intentions and scopes, integrating non-typical users of technology in the design considerations and requirements for products and services in the Industry 4.0 era [31-34].

This paper aims to build an integrated vision of the descriptions and perceptions on the digital gap and the divide caused by it throughout the publications of this century as a starting point for typifying the design requirements for flexible technology integration. Other mappings have offered a view of implications and strategies [35] to cope with the phenomenon consequences and its impact, bringing structure to the concept 
and the relevant interconnections with other issues [36,37]. Several mappings focus on social inequalities [38,39] and education reach [40,41]. Additionally, systematic literature reviews on this issue offer a set of conceptualizations' evolution descriptions [42], the status of a specific dimension of the phenomenon [43], and some referring to vulnerable groups $[37,44,45]$. The mapping presented in this article and the correspondent analysis focuses on identifying the papers offering a view on vulnerable populations, including them in a single group. It is also relevant for this approach to observe the possibilities scope reported on in the retrieved papers. The conclusions refer to the educational practice and research implications, along with the limits of this study and future research opportunities and possible directions.

\section{Methods}

\subsection{Context}

To learn and identify the strategies and ways to offer accessible approaches to the design of technological devices and ICTs, we must build an integrated perspective on how this issue has been attended. This systematic mapping focuses on vulnerable groups and the digital gap concept to assess the progress in academic research towards acknowledging its scale and implications as a form of discrimination. This mapping is part of ongoing research pursuing validated tools for the Smart, Sensing and Sustainable Products and Services Systems ( $S^{3}$ PSS) [46-49], observing the requirements of flexible technology integration [50] for those who are considered non-typical users of technology [51]. This consideration includes individuals who suffer or at least experience a digital gap due to lacking resources, literacy, or skills to fully use and benefit from technological devices in the perspective of $S^{3}$ PSS.

On the other hand, typical users of technology and technological devices should be those individuals who have access to use and benefit from intelligent, sensing, and innovative products, services, and systems. It also includes individuals who have full access to connectivity and information to learn or acquire technological literacy or skills to benefit from specialized products, services, and systems.

Building a framework and setting the contribution of research, it is crucial to identify the state-of-the-art approaches and conceptualizations of a field of study. In general terms, a systematic mapping and its subsequent systematic review summarize the studies about a specific topic. They can also identify knowledge gaps in current research and consequently highlight opportunity areas for further investigation while building a framework to plan new research activities [52]. The systematic literature mapping (SLM) method followed in this paper aimed to create a general view of the digital gap as a subject of study but also include relevant terms for a detailed view on the relations and tensions in this topic. It also facilitated a later systematic literature review (SLR) of the available literature. Both processes make it possible to understand the most challenging elements of an $S^{3}$ PSS for non-typical users of technological devices [53].

\subsection{Framework}

It is worth mentioning that systematic literature mapping and a systematic review of literature are different processes with different objectives. The first process in building the overall framework for research should be an SLM. It brings structure to the documents retrieved in a reference search, analyzing the "type of research reports and results that have been published by categorizing them (and obtaining) a visual summary, the map, of its results" [54] (p. 2). Thus, the SRL is a secondary process that aims to build a reference framework and assess the potential contribution of given research through an in-depth literature review of research methodology and results. 
For this paper, we used a protocol taken from Kitchenham's proposal [52] and observed others [55] who successfully conducted systematic mappings in the same stages. Figure 1 is a schematic representation of the protocol followed for this review. The methodological process in this SLM protocol includes defined stages and steps [56] suitable for the main research area: design and engineering. It also allows this work to connect with other disciplines, which is useful for further diverse studies. Designing a protocol, conducting a review, and assessing it are three different stages, with defined steps for each one. In the planning stage, the first step is identifying the topic for the primary research, and the second must be the protocol development.
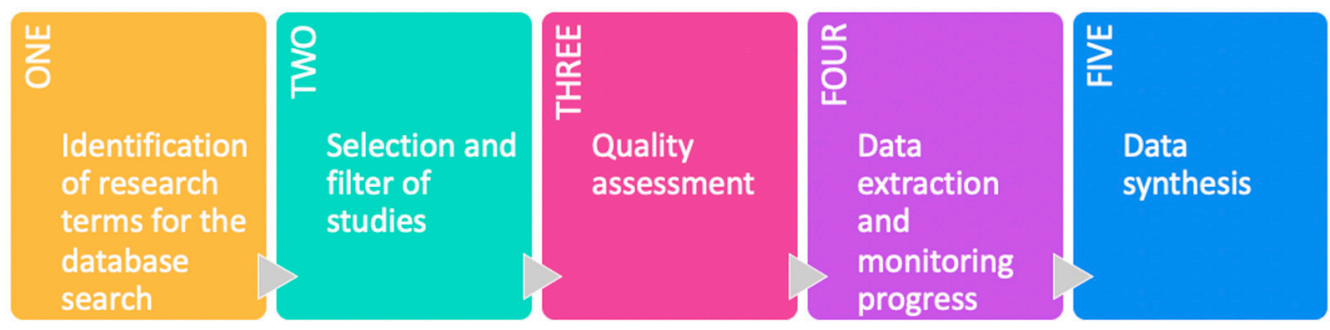

Figure 1. Diagram of protocol process from Kitchenham's proposal [52].

The conceptual framework, defined by Jabareen as "interlinked concepts that together provide a comprehensive understanding of a phenomenon or phenomena" [57], guides the building process of an SLM. To identify the research terms or the "concepts linkage", we made various attempts to find the right combination of keywords and criteria for the database search of the documents. The related terms were evident at the beginning of this work because there was a prior intention to map the digital gap. However, it became clear that the digital gaps exist in various situations, contexts, and among groups of people [58].

Although a quick search in Scopus found that the term "digital gap" drew 408 document results (Title, Keywords, Abstract), we were concerned about not obtaining valuable sources for mapping those documents. A second search using the terms "digital gap" AND "inclusion" helped refine the search, resulting in only 40 papers. It was helpful to observe that the initial search increased 1,459 document results when using the search query: (("digital gap") OR ("technological gap")).

After searching with other combinations, it became clear that to narrow the search to a manageable number; the query should be related to vulnerable groups who have experienced or coped with the digital gap since the beginning of the millennium, thus, looking at documents from 2000 to the present [13]. The final additional terms for the search were "gender" [59], "age *" [60], "rural" [61], and "disab *" [62].

The search queries in both databases, being (("digital gap") OR ("technological gap") AND ((gender) OR (age *) OR (rura $\left.l^{*}\right)$ OR (disab $\left.\left.{ }^{*}\right)\right)$ ), lead to 89 results in WOS and 137 in Scopus; 226 results in total. There were 46 duplicate documents eliminated, leaving 180 unique documents. Then, a thorough revision results in the exclusion of 22 documents due to documents referring to other definitions of digital gap (used in fields such as chemistry or dentistry) or technological gap (defined as lack of advanced machinery) and one unretrievable document (with missing data). Based on the PRISMA Statement [63] Figure 2 shows the papers' selection and refining process. 


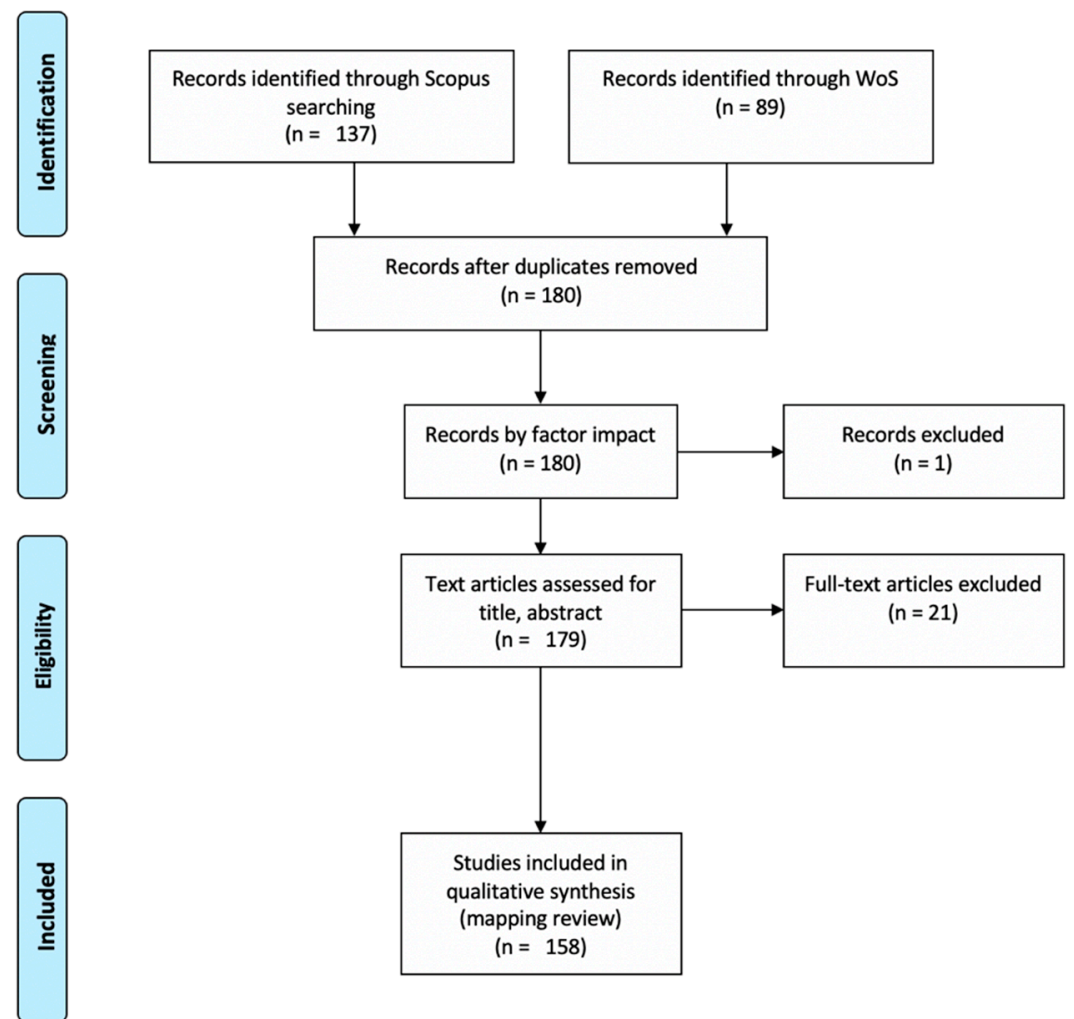

Figure 2. PRISMA 2009 flow diagram for the systematic literature mapping.

For the second step, we selected studies from two bibliometric databases, Scopus and Web of Science, to balance the retrieved disciplines and include Humanities, Social Sciences, Engineering, Sciences, and Life Sciences [64,65]. These databases are complementary yet not mutually exclusive; using both brings an advantage of having two sources of information that are "different in scope, data volume and coverage policies [ ... ], by including a greater number of journals, papers and signatures." [66] (p. 8). Despite other databases that might be helpful for this task, the research team agrees with the conclusion of a 2021 study that states that Web of Science and Scopus are "remain the two major and most comprehensive sources of publication metadata and impact indicators." [67] (p. 47). The amount and quality of the retrieved papers confirm that every field of interest, the required language for the analysis, and the results volume are suitable and adequate for this research task.

Due to feasibility factors, it was convenient to retrieve only articles from journals, excluding books, conferences' proceedings, reviews, editorial materials, and emerging sources or under-review papers. This type of search restriction has a double purpose; the first entails time and resources available for reviewing documents. The second one relates to only mapping peer-reviewed papers [68].

The protocol of Petersen et al. [54] has the definition of research questions as a primary step for a rigorous systematic mapping study. We defined six research questions (RQs), described in the following section. These RQs led the mapping from stage three and beyond in a second process to reach a more comprehensive understanding of the digital gap phenomenon. The third stage prescribes a quality assessment of the retrieved documents in both databases.

The data extraction and monitoring process facilitate the answers to the research questions. This stage's work adds layers of information, leading to identifying categories, approaches, and priorities for the systematic literature review (SLR), narrowing the number and diversity of the documents to be analyzed. Finally, data synthesis, which has a close relationship with the research questions, guided the decision-making process of the previous stages. For the data extraction and synthesis, the RQs represented the task's core: attaining a summary and providing the input for the SLR. 


\subsection{Definition of Scope}

Following the work of Kitchenman et al. [69], our research questions targeted the articles' topics, allowing the construction of a conceptual framework of flexible technological integration to reduce or bridge the digital gap. This research also highlighted some research trends and opportunities for future research. Table 1 shows the RQs and the desired outcome for each.

Table 1. Research questions for the SLM.

\begin{tabular}{|c|c|}
\hline Research Questions & Desired Outcome \\
\hline $\begin{array}{l}\text { RQ1a: How many studies are in the WOS and } \\
\text { Scopusdatabases from } 2000 \text { to 2021? } \\
\text { RQ1b: Which approach was used for the research } \\
\text { in the articles found? }\end{array}$ & $\begin{array}{c}\text { A number of pieces in Scopus and WOS } \\
\text { Number of duplicate articles } \\
\text { Number of qualitative studies } \\
\text { Number of quantitative studies } \\
\text { Number of mixed-methods studies }\end{array}$ \\
\hline $\begin{array}{l}\text { RQ2: Who are the authors of the most cited } \\
\text { articles? }\end{array}$ & $\begin{array}{l}\text { Most cited authors } \\
\text { Most cited articles }\end{array}$ \\
\hline $\begin{array}{l}\text { RQ3: What is the geographical distribution of the } \\
\text { principal authors? }\end{array}$ & $\begin{array}{c}\text { Countries where the authors are from } \\
\text { Countries in which the issue is a common } \\
\text { concern }\end{array}$ \\
\hline $\begin{array}{l}\text { RQ4a: Which journals publish the most articles on } \\
\text { this topic? } \\
\text { RQ4b: What are the journals' rankings? }\end{array}$ & $\begin{array}{l}\text { Journals and publications } \\
\text { Journals' rankings: Q1, Q2, Q3, Q4 (or not } \\
\text { available) }\end{array}$ \\
\hline RQ5: What are the topics in this research area? & $\begin{array}{l}\text { Who suffers from the digital gap and in } \\
\text { which environments }\end{array}$ \\
\hline $\begin{array}{l}\text { RQ6: What are the opportunity areas in this line of } \\
\text { research? }\end{array}$ & $\begin{array}{l}\text { Accessible or flexible technology strategies } \\
\text { and digital divide diagnosis }\end{array}$ \\
\hline
\end{tabular}

This SLM aimed to gather helpful information about the requirements for the design of $S^{3}$ PSS. Therefore, the RQs' outcomes should help better understand how to address the digital gap and the remaining gaps in the years to come. Accordingly, the RQs facilitate learning about the inequalities caused by the digital gap in specific world regions. In addition, the categories and subcategories identified in the retrieved literature conveniently throw light on available literature about accessible, integrated technology. Table 2 describes the strategy and the criteria descriptions that arrived at the 158 documents used to answer the research questions.

Table 2. Search strategy for the SLM.

\begin{tabular}{ll}
\hline Strategy & Description \\
\hline Databases & WoS and Scopus \\
\hline & $\begin{array}{l}\text { Topic in (SCI-EXPANDED), Social Sciences Citation Index (SSCI), Arts \& } \\
\text { Humanities Citation Index (A\&HCI): } \\
\text { "digital gap" OR “technological gap" AND gender OR age * OR rural * OR } \\
\text { disab* }\end{array}$ \\
$\begin{array}{l}\text { Search string or } \\
\text { Keywords in Web } \\
\text { of Science database }\end{array}$ & $\begin{array}{l}\text { Citation Index (SSCI) or Science Citation Index Expanded } \\
\text { (SCI-EXPANDED) or Arts \& Humanities Citation Index (A\&HCI) NOT }\end{array}$ \\
& $\begin{array}{l}\text { Document Types: Proceedings Papers or Early Access. Timespan: 01 } \\
\text { January 2000 to 01 August 2021 }\end{array}$ \\
\hline $\begin{array}{l}\text { Search string or } \\
\text { Keywords in }\end{array}$ & $\begin{array}{l}\text { Article title, Abstract, Keywords: } \\
\text { "digital gap" OR “technological gap" AND gender OR age * OR rural * OR } \\
\text { disab * Refined by: PUBYEAR > 1999 AND LIMIT-TO DOCTYPE, "article" } \\
\text { AND LIMIT-TO “journal." }\end{array}$ \\
\hline
\end{tabular}


Table 2. Cont.

\begin{tabular}{ll}
\hline Strategy & Description \\
\hline Timeframe & 2000 to 2021 (1 August) \\
\hline Document type & Article \\
\hline Language & All \\
\hline Study field & Unspecified \\
\hline Type of access & Unspecified \\
\hline \multirow{2}{*}{ Inclusion criteria } & $\begin{array}{l}\text { Primary studies about digital gap } \\
\text { Studies describing the digital gap related to age, gender, rural (context) and } \\
\text { disabilies. } \\
\text { Only articles in journals }\end{array}$ \\
\hline Exclusion criteria & $\begin{array}{l}\text { Duplicate articles of the same research } \\
\text { Studies without complete data (unretrievable documents) } \\
\text { Studies unrelated to the concept of the digital gap in technology access } \\
\text { Systematic literature mappings }\end{array}$ \\
\hline
\end{tabular}

\section{Extraction of Relevant Findings from Articles}

The data retrieved from both databases included the author, title, year, abstract, source title, citations, author's affiliation, and country. The analysis for the findings identification was made using a spreadsheet to categorize the information and answer the research questions. For the data extraction, categorizations were created from the information provided in a first step from the title, in a second review from abstracts. When needed, the full text was used for clarification.

As data extraction has to involve useful and defined categories, which must add value to answer the research questions, we followed Petersen et al. recommendations on the evolution of classification schemes while doing the data extraction, like adding new or merging or splitting existing ones [54]. The starting point was the topics related to the keywords used in the search strings, used as categories that were combined and redefined as needed to extract relevant and constructive findings.

Content analysis, a qualitative technique for making inferences from a focal text in a social context in an objective manner [70], was used for the data extraction. The components considered were both mechanical and interpretative; the first for the data organization into the categories, and the second to determine the critical data for answering the research questions. As it is required to avoid any bias in the analysis, a triangulation with three peers [71] was performed to clarify possible answers to the queries and research questions. In case of discrepancies, the peers reviewed the information, reached agreements on answer selections, and approached $100 \%$ data verification. For the answers synthesis, graphic representations were generated to summarize each RQ analysis presented in this report. The analysis data are presented in an integrated spreadsheet, including an ID number to identify every paper correctly, facilitating referring to them throughout this report. The dataset is available and open at https:/ / repositorio.tec.mx/handle/11285/638751 (accessed on 10 November 2021).

The categorization of the data followed the RQ analysis, starting with the identification of the methodology for each paper, throughout a search of relevant information to extract the documents that discuss ICT development or implementation for the accessibility and the inclusion of vulnerable populations as an attempt to bridge the digital gap. In Section 6, for the SLR to be performed as a future study continuing this work, the PRISMA Statement workflow chart shows the selection and depuration $\mathrm{f}$ the retrieved and mapped documents.

3.1. RQ1a: How Many Studies Are in the WOS and Scopus Databases from 2000 to 2021; RQ1b: Which Approach Was Used for the Research in the Articles?

The filtered database contains 158 documents that form the mapping core material. The classification for the type of study came from the abstract or the keywords and title when 
needed. Some abstracts were unclear about the approach, and in fewer cases, reviewing the article corpus for more information was required. Figure 3 shows that the approach distribution in the papers is relatively even, between qualitative, quantitative, and mixed methods.

The selected documents shed light on the diversity of approaches for this topic's study, allowing us to observe that some papers report empirical evidence on technological acceptance. In contrast, others account for a disparities description among certain world regions and some population groups. However, there is no relation between the approach type and the journal theme content. This information helps to understand the issue's multidimensionality and the diversity of possibilities to embrace its solution.

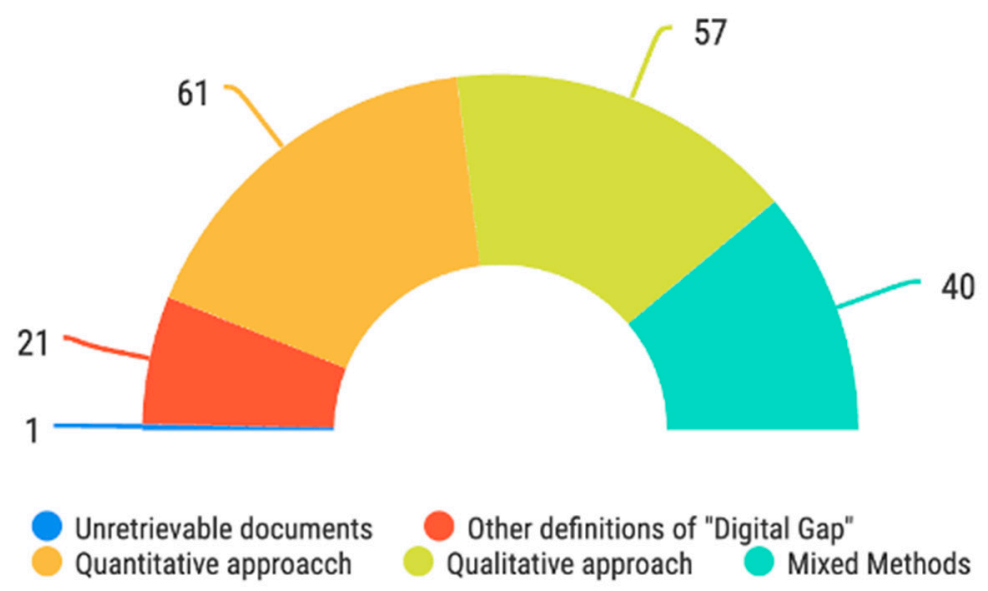

Figure 3. Filtered database.

\subsection{RQ2: Which Are the Most Cited Papers?}

The most cited papers shared a specific quality: they referred to a digital divide diagnosis in the European Union. The publishing journals with the first five most cited papers were (a) Energy Economics; (b) Empirical Economics; (c) Telecommunications Policy; (d) Information and Management (with two papers); (e) Universal Access in the Information Society. The top three most cited articles were paper ID 105, with 151 citations; ID 106 (from the same author) with 126 citations; paper ID 150, cited 114 times. Those papers leading in citations concur that the European Union countries have a digital divide.

Fewer citations happen for papers in every ranking quartile. Table 3 shows the most cited journals with the article ID number. The list shows that only ID 150 belongs to journals with more than three publications on this topic and the most cited papers. Additionally, there are 40 non-cited articles on the list and 27 papers cited once. Non-cited and less-cited publications did not correlate to the journals' ranking or the attended issues.

Table 3. Most cited papers in journals with more than three publications.

\begin{tabular}{|c|c|c|c|}
\hline Journal & ID & Cited & Quartile \\
\hline \multirow{5}{*}{ Sustainability } & 22 & 16 & \multirow{5}{*}{ Q2 } \\
\hline & 124 & 4 & \\
\hline & 83 & 3 & \\
\hline & 23 & 2 & \\
\hline & 126 & 1 & \\
\hline \multirow{6}{*}{ Telecommunications Policy } & 150 & 114 & \multirow{6}{*}{ Q1 } \\
\hline & 84 & 20 & \\
\hline & 56 & 3 & \\
\hline & 115 & 1 & \\
\hline & 45 & 0 & \\
\hline & 152 & 0 & \\
\hline
\end{tabular}


Table 3. Cont.

\begin{tabular}{cccc}
\hline Journal & ID & Cited & Quartile \\
\hline & 73 & 70 & \\
Universal Access in the Information Society & 61 & 3 & Q1 \\
& 7 & 0 & \\
\hline
\end{tabular}

\subsection{RQ3: What Is the Geographical Distribution of the Principal Authors?}

It is interesting to observe that the digital gap is a global concern, but the developed nations are mostly leading the discussion. Many articles in the search discussed the digital gap (or technological division) in specific regions or among the population of a given country. However, fewer observations took place in underdeveloped countries: only ten from South America, there was one paper from Brazil, two from Colombia, one from Peru, one from the Dominican Republic, and five from Chile. Additionally, the search retrieved six articles referring to African contexts: one from Egypt, one from Ganha, another from Uganda, and three from Nigeria. There were six papers from Malaysia, one from Indonesia, and another from Australia.

Of the 134 papers published by authors from countries in the northern hemisphere, 37 were from Spain, which is the most frequent result in the search by geographic distribution(Figure 4). Spain's predominance is evident in the highlighted regions in Figure 3, where one can observe that most papers came from European countries.

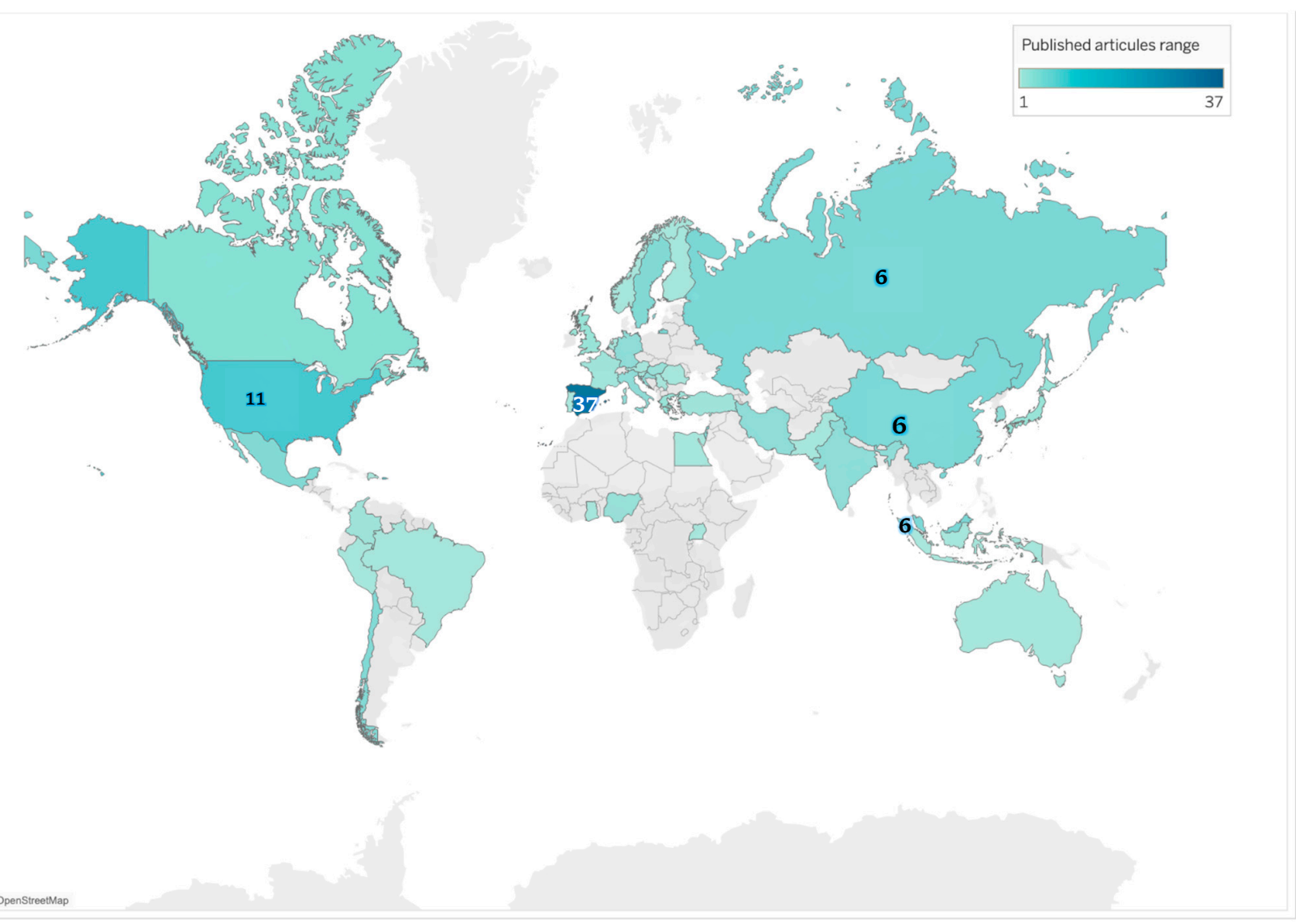

Figure 4. Geographical distribution of principal authors.

The disparity mentioned above occurs in a timelapse of more than two decades. Although it was found that 22 papers from underdeveloped or developing countries show consistency in specific topics of interest: 19 of them discuss ICTs, 14 articles include a 
discussion on social issues, and 11 documents also focus on education. There could be a possible relation between the attention to the digital division caused by the digital gap and people's coverage and access to connectivity or ICTs. A possible inference is that regions without availability and accessibility to ICTs are mainly centred on equal essential services for people. In developed countries, the focus can be related to more complex access to specific groups. Possible future work might address its efforts on answering this assumption.

Interestingly, the GSMA web page displays a Mobile IoT Deployment Map showing that the global coverage of technology allowing devices to communicate with each other covers mainly developed regions and developing countries. Other areas, like most African countries, a large part of Latin America, and some Asian countries lack the infrastructure that allows higher levels of technological impact and its benefits.

As mentioned earlier, despite the availability of coverage, the digital divide exists. When comparing the geographical distribution of the principal authors' map (Figure 3) and the Mobile IoT Deployment Map from the GSMA "Internet of Things" report [72], one can observe that the discussion around the digital gap occurs in regions that already have services and infrastructure. Additionally, it becomes clear that those countries that are not studying the digital gap are also far away from the possibility of providing digital training and education for their people.

\subsection{RQ4a: Which Journals Publish More Articles on This Topic?; RQ4b: What Are the Journal Rankings?}

The results highlighted that there are considerable differences in citations for some articles. The number of article citations can measure the relevance of the mapped papers. Additionally, the journal's ranking is pertinent for this mapping; the journals' permanence shows that this topic has transversal relevance. Nevertheless, in the quartile journals' ranking (Figure 5), this SLM showed no significant differences among the ranking distribution.


Figure 5. The proportion of ranking in publishing journals.

There were 67 journals indexed in the first quartile, two of the three with more than two publications on this topic. The third journal with more than two publications on the digital gap was in the second quartile and 25 more journals. There were 32 journals ranked as Q3 and 23 in Q4; 10 journals lacked available data on their rankings.

One finding from this analysis is the topic's relevance as an antecedent to identify possibilities and challenges towards eliminating or reducing the digital gap. The sum of the Q1 group's citations of the articles in this group sums up 1166 citations, having only 12 papers with no citations. Otherwise, the total of Q2, Q3, and Q4 showed 235 citations. The findings are valuable for researchers exploring the topics addressed in this mapping to select a suitable journal for their research. 


\subsection{RQ5: What Are the Topics in This Research Area?}

Topics categories came from the search terms referring to vulnerable groups: gender [59,73], older citizens [74-76], indigenous peoples (or first nations) [44,77], and people with disabilities $[1,8]$. When discussing equity and inclusion, the latter is an approach to remediate the lack of equity and insert fairness in a context [78,79]. Consequently, the second group of topics helped categorize the mapped documents: the context in which the vulnerable groups mentioned above experienced the digital gap: social, educational [80,81], ICT [82], and economic [17]. The items used for the mapping were, in order of priority: (a) author's keywords; (b) database keywords (applicable only for WOS); (c) title; (d) abstract; (e) full article text.

For the categorization, additional terms referring to the same topic were added. Table 4 explains the terms for each topic category. These were arranged in triennial groups (i.e., three-year periods) to observe the evolution of the subject through the first two decades of the 21st century. It is worth mentioning that the findings were close to what we expected concerning the non-existence of published papers on some topics like disability or gender in the first triennial periods.

Table 4. Key terms for categorization.

\begin{tabular}{|c|c|c|}
\hline Cluster & Categorization Topic & Key Terms \\
\hline \multirow{4}{*}{ Context } & Social & Divide; justice; inclu (for inclusive, inclusion); equity. \\
\hline & Education & $\begin{array}{l}\text { educ (for education, educational); learn (for learner or } \\
\text { learning); skill, teach (for teacher, teaching, teach) } \\
\text { literacy; train (for training, trainer, trainee); scho (for } \\
\text { scholar, school); student. }\end{array}$ \\
\hline & $\begin{array}{l}\text { Information and } \\
\text { Communication } \\
\text { Technologies }\end{array}$ & $\begin{array}{l}\text { ICT; comm (for communication, communications); } \\
\text { tech (for technology, technologies, technological); } \\
\text { internet. }\end{array}$ \\
\hline & Economic & $\begin{array}{l}\text { econom (for economy, economics, economic); financ } \\
\text { (for finance or financial); product (for production, } \\
\text { productivity, products). }\end{array}$ \\
\hline \multirow{4}{*}{$\begin{array}{l}\text { Vulnerable } \\
\text { population }\end{array}$} & Gender & $\begin{array}{l}\text { wom (for woman or women); gender; femini (for } \\
\text { feminist or feminism). }\end{array}$ \\
\hline & Age & $\begin{array}{l}\text { old (also for older); age (also for ageing); elder (also } \\
\text { for elderly). }\end{array}$ \\
\hline & Disabilities & $\begin{array}{l}\text { disab (for disability or disabled-the term used in the } \\
\text { 20th century); accesib (for accessible or access); } \\
\text { inclusi. }\end{array}$ \\
\hline & Ethnics & $\begin{array}{l}\text { Indigenous; et (for etnia, ethnicity); rural; low } \\
\text { (income); socioeconomic; poverty. }\end{array}$ \\
\hline
\end{tabular}

Addressing issues such as gender, ageing and ethnics, or rural contexts, can shed light on prospects for future forms of answering to the demands represented by these groups. A relevant finding was the low prevalence of papers on ageing, gender, or ethnicities in the last years. At the same time, the social dimension increased exponentially (see Figure 6) as there is an evident absence of attention to important topics that might need further consideration. 


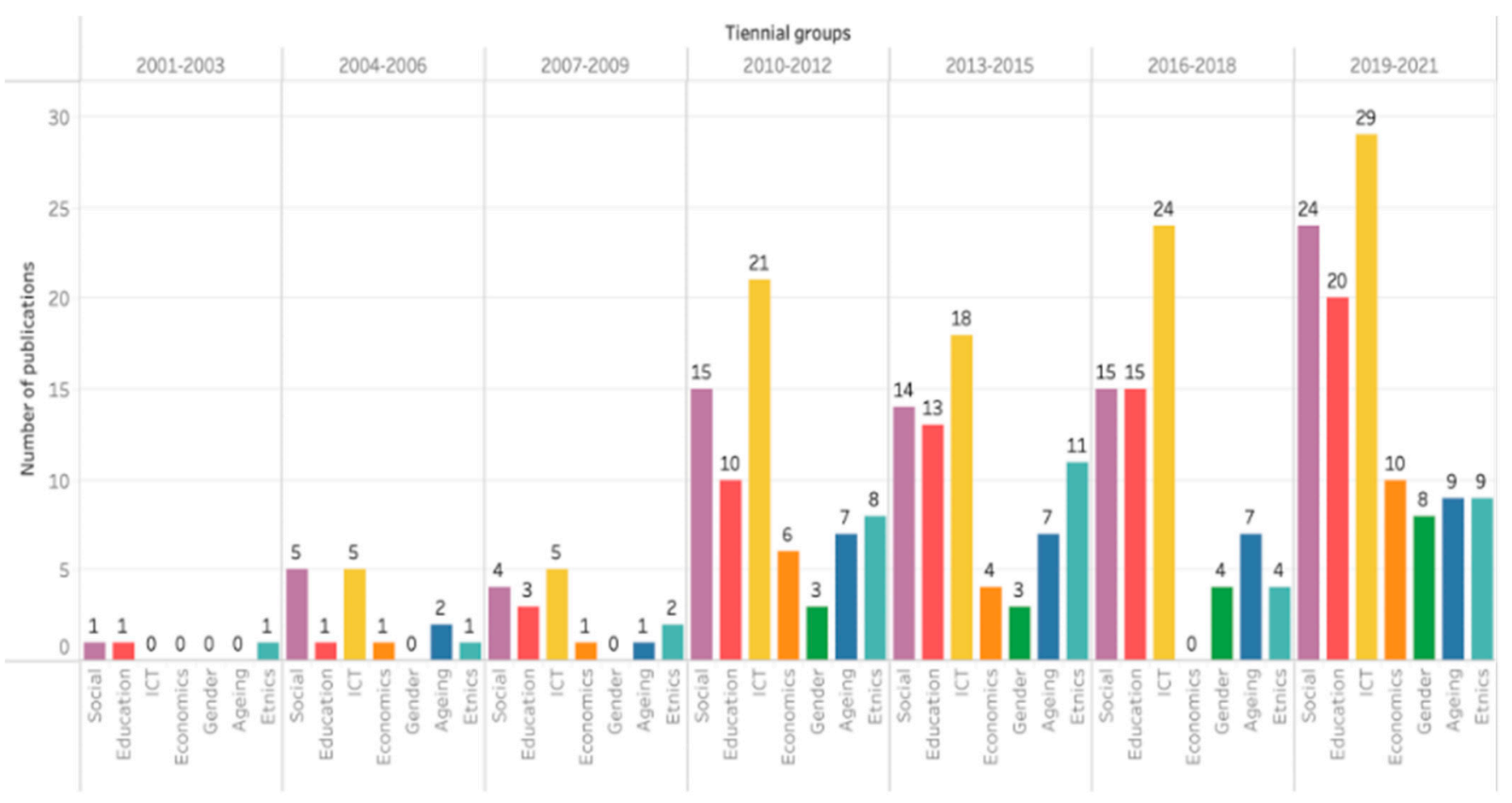

Figure 6. Topics in articles across time by triennial groups.

The analysis also revealed a few articles on economic issues throughout the past 20 years. A relatively low number of papers on this topic might be linked to a lack of understanding of the opportunities to create accessible technology to foster sustainable solutions for global and complex problems, such as health and safety. Future research can address efforts towards connecting possibilities from including vulnerable groups to increase the impact and coverage of social services in a sustainable combination throughout time and frontiers. By ideating and creating accessible $\mathrm{S}^{3} \mathrm{SPP}$, future innovation and development can take technology closer to a broader impact with inclusive solutions.

\subsection{RQ6: Which Papers Discuss Accessible or Flexible Technology and Digital Gap Diagnostic?}

As mentioned before, flexible technology integration aims "to fully involve the human during the entire system-engineering process" [83]. This research selected 65 documents focusing on accessible technology (Figure 7), and 114 reporting a digital divide in some world regions, the European Union, the most common.

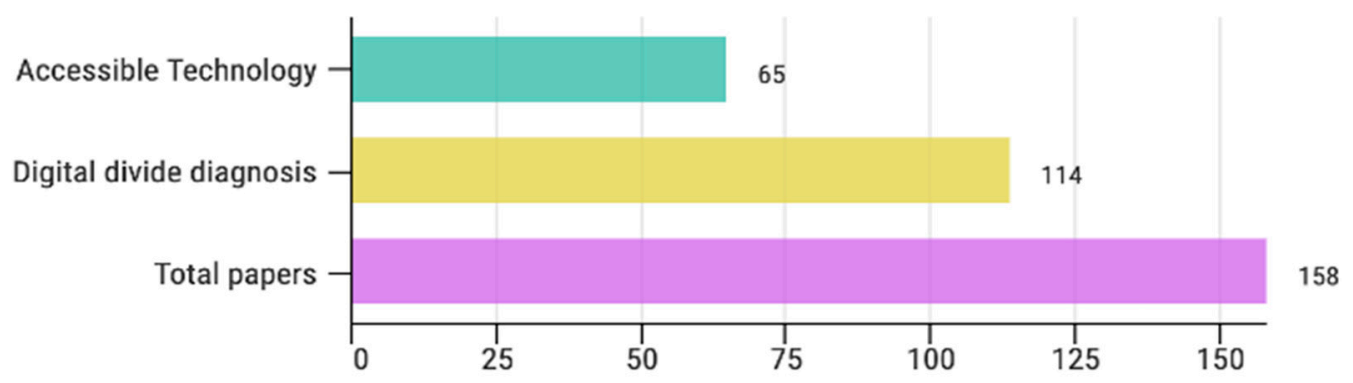

Figure 7. The number of articles addressing the digital gap or strategies to bridge the digital gap.

The categorization revealed that 21 articles explored both topics. It is noteworthy that not every paper addressed a specific technology or one that could be categorized as flexible or having a seamless human-system integration [50]. A second process of delimiting with the inclusion and exclusion criteria [84] determined the articles to review for the 
SLR; a crucial criterion is including only those papers reporting empirical evidence of implementing flexible technology with human-system integration.

\section{Discussion}

Several questions emerged during the analysis, some to discuss in future studies; others, arising from the research, led the discussions. The ultimate goal of this research was to identify empirical evidence of efforts to facilitate bridging the digital divide. The digital gap has various causes, consequences, and interconnected issues. The reasons are often related to the availability of ICTs and infrastructure for those technologies to function fully. At the same time, the consequences are seen on a deep division in people's life quality. The mapping showed no specific research approach for the studies in this area, and there was a vast diversity in the applications and orientations among the retrieved papers. As many have stated before, the digital gap is not a problem that affects only a few people; on the contrary, as the world expands through ICT, the digital gap manifests in various contexts for many reasons $[19,85]$. Therefore it must be observed and studied from multiple perspectives and orientations. Researchers might use qualitative, quantitative, or mixed methods to describe the tangle of factors and scenarios involved.

A crucial finding of this work was observing who is taking the lead in analyzing the digital gap. RQ3 led to evidence that less developed countries in Africa, Asia, and Latin America are not discussing this issue. In addition, some studies indicated that even in developed countries, there were manifestations and consequences of the gap [20]. Consequently, to include the world's poorest regions needs and perspectives is required to develop comprehensive solutions to the digital gap problem [41]. One initial consideration could be a possible bias in the results due to under-representing studies in the world's most impoverished areas. This disparity could keep concerning the states' capabilities to invest and offer ICTs, studying that could be a matter for future studies to cover.

Considering the current state of education, one might have inferred an increasing interest in this topic before this mapping. However, only one journal has published six articles on this topic, and one has five pieces; one journal ranks in the first quartile and the other in the second. On the one hand, publishing articles on a topic increasingly researched during the decade is probably one of the journals' objectives [84]. On the other hand, we found that no one particular journal led with an absolute majority of publications on the digital gap topic, even though the analysis confirmed the initial supposition that the number of articles increased throughout the time. Therefore, future researchers could consider choosing any journal from the first quartile, addressing this issue from any possible perspective, according to the journal's topic.

In addition, the grouping of articles for RQ5 revealed that some categories of the cluster "vulnerable population" emerged during the second decade of this century; others are discussing "context" increased as well. For instance, the categories "disability" and "gender" have been visible only since 2009. The number in the category "economics" increased but fewer compared to "social" and "ICT," the latter being the most extensive group in the categories list. The growth of ICTs correlates closely with the digital transformation that the world has experienced in the last decade [18], which has aimed to answer emerging needs or perform operations more efficiently [17] (p. 124). The growth of topics and discussions about the digital gap highlights the interconnections and exponential impact in various contexts, levels, and dimensions; consequently, researchers must continue studies for justice and people's legitimate rights worldwide.

For the last research question, RQ6, the second categorization narrowed the work to the next stage: the systematic literature review. The majority of pieces reported a digital divide diagnosis, and 64 pieces presented empirical evidence of ICT implemented to improve the access and equity of its users, one-third of them written to diagnose the digital divide in a specific group or region. Digital inequalities among disadvantaged communities are complex problems with many interconnected layers [58]. Flexible or adaptable technology [50] for non-typical users [53] or vulnerable populations could mitigate or eliminate 
the digital divide. The SLR will be focused on the 34 papers that offered a view of those efforts to close the gap through information and communication technologies.

\section{Implications, Limitations, and Future Work}

For the educational practice, this mapping's implications rely on including the design considerations for inclusive and accessible ICTs in the design or engineering programs. Addressing the ICTs design in a diverse approach might foster students' innovation capabilities and sensibility towards vulnerable populations during the design process.

For the design practice, decision-making, and policy agenda, the findings presented in this document imply that there is a possibility of bridging the digital gap using technology as a responsive, empathetic tool. Reaching the Sustainable Development Goal 4 is not just about facilitating broadband services or accessible devices but allowing people to acquire capabilities in the trial-and-error process. Allowing everyone to thrive and achieve skills that will improve their livelihoods will bring equity in education and better opportunities through technology development for a more promising future.

Regarding this paper's contribution, we intend to provide a framework for the design methods developed for the research community that will consider the requirements linked to non-typical users' characteristics and skills during the design process. One of this work's limitations is not including other languages than Spanish and English in the mapping. Further research might follow the methodology to cover this aspect, finding other studies regarding accessible and inclusive ICTs to close the digital gap.

Another limitation of this mapping is using only two databases: Web of Science and Scopus. These two were selected because the two databases are diverse in the representation of topics and are considered both wide and comprehensive enough as sources of publication metadata and impact indicators. However, using other databases should complement indepth and scope the findings reported here.

As mentioned above, this mapping will continue with the correspondent systematic literature review, which will use 64 of the 158 documents retrieved from the initial search. Those papers have been screened to identify the 34 articles discussing or reporting accessible or inclusive approaches or strategies that use ICTs to address vulnerable populations. A quality assessment will be performed to characterize the ICTs' features to build a framework for self-adaptable products and service systems through the consideration of those behind the digital gap: older adults, people with disabilities, indigenous peoples, or women, who suffer a digital divide.

\section{Conclusions}

This document presents a mapping of 180 papers published in the first 21 years of the 21 st century about the digital gap and vulnerable people. The analysis revealed how this had become an increasing concern among scholars and researchers and the topics that have gained attention while others still can be studied in depth. The impact and consequences of the inequalities caused by the digital gap still have some research opportunities, primarily focusing on topics related to various worldwide contexts among disadvantaged groups of people, including older adults, people with some disabilities, marginalized women, or indigenous peoples.

A first finding showed that digital gap studies are a transversal topic due to the equivalence in numbers on qualitative, quantitative, and mixed methods applied to the studies. This issue shows a multifactorial origin, affecting access, resources availability, literacy, skills, capabilities, and even location in a diversity of unequal contexts and environments where it occurs. These environments might be social, economic, or educational and related to justice and rights, productivity, health, and interactions. Thus, a meaningful conclusion is a comprehension that to increase the solutions effectiveness, approaches and tools must be transdisciplinary to assure attending the highest number of factors and constraints in creating accessible strategies and initiatives to bridge this gap. 
Most papers and the most cited ones belong to authors from the European Union, followed by other developing or developed Asian and North American countries. Hence, there is a possible underrepresentation of the less developed or emerging countries. Consequently, for future work, it is required to comprehend how the digital divide issue is attended as a phenomenon causing a divide in those regions that were not founded in this study. Researchers interested in building a more holistic vision of this issue could perform a future analysis using keywords related to those contexts or world regions to understand this problem worldwide.

During the last two decades, the evolution of topics showed that most published studies present empirical evidence of ICTs implementation. There is an opportunity to group those articles into two categories: research on flexible technology to achieve inclusivity or equity and articles reporting technology acceptance. The selected documents for an SLR in future work come from the first group following the protocol of identifying the state-of-the-art, flexible, integrated technology to benefit the non-typical user. It was found that the fewer documents in this mapping report this type of technology, so the review will focus on the description of ICTs built for accessibility and inclusion.

Consequently, it is possible to infer that a novel approach and an innovation opportunity is designing ICTs for accessibility and inclusion. A potential field of research is addressing the digital divide problem in an unusual direction: starting with what can be achieved by vulnerable groups, not by patronizing their abilities, but by truly understanding their context and needs before the design process, allowing them to catch up faster with socio-technical transitions. In order to do that, it is required to understand what has been done in ICT development, especially for vulnerable groups, and what can still be done to address this issue.

Finally, from this SLM, it was possible to conclude that the findings and results are valuable to identify the design requirements for inclusive products and service systems in the $\mathrm{S}^{3} \mathrm{PSS}$ construct because it is possible to determine the digital gap's impact on 21stcentury society as a modern form of inequality. It becomes urgent to visualize the possible alternatives to mitigate or eliminate the gap.

As a potential solution to bridge the digital gap, we propose taking the information generated by individuals from vulnerable groups to understand their needs and struggles when interacting with technological devices. The most common interactions and behaviour from a novel or untrained user with these artefacts and their interfaces might provide keys for accessibility, inclusion, and affordability in the ICTs. Regarding this, it was observed that the smallest number of papers describe ICTs features or characteristics that offer solutions for people that might be experiencing the digital gap.

A substantial contribution for innovation in ICTs devices design can be reached if the combination of schemes followed by the studies reporting these solutions is used to identify the better solutions: the most accessible, inclusive, and affordable ones. Throughout a systematic literature review that will be conducted a future work, those schemes, and answers will be analyzed searching design methods and techniques that might uphold controlled, replicable, and predictable results in the innovative technological solutions for the emerging problems of people around the world.

Author Contributions: Conceptualization, I.A.-I.L. and M.S.R.-M.; methodology, I.A.-I.L. and M.S.R.M.; validation, R.B.-B. and M.S.R.-M.; formal analysis, I.A.-I.L.; investigation, I.A.-I.L.; resources, I.A.-I.L.; data curation, I.A.-I.L.; writing—original draft preparation, I.A.-I.L.; writing-review and editing, I.A.-I.L., R.B.-B. and M.S.R.-M.; visualization, I.A.-I.L.; supervision, A.M. All authors have read and agreed to the published version of the manuscript.

Funding: This research received no external funding.

Institutional Review Board Statement: Not applicable.

Informed Consent Statement: Not applicable. 
Data Availability Statement: The dataset presented in this study is openly available at https:// repositorio.tec.mx/handle/11285/638751 (accessed on 10 November 2021).

Acknowledgments: The authors acknowledge the technical support of the Writing Lab, Institute for the Future of Education, Tecnologico de Monterrey, Mexico, in the production of this work.

Conflicts of Interest: The authors declare no conflict of interest.

\section{References}

1. World Economic Forum. Error 404: Barriers to Digital Inclusivity. Reports. 2021. Available online: http://reports.weforum.org/ global-risks-report-2021/error-404-barriers-to-digital-inclusivity / (accessed on 18 August 2021).

2. Ayob, A.H. E-commerce adoption in ASEAN: Who and where? Future Bus. J. 2021, 7, 4. [CrossRef]

3. UN News. Global Perspective Human Stories. 2020. Available online: https://news.un.org/en/story/2021/04/1090712 (accessed on 18 August 2021).

4. Wolrd Bank Open Data. International Telecommunication Union World Telecommunication/ICT Indicators Database. Mobile Cellular Subscriptions (per 100 People). 2021. Available online: https:/ / data.worldbank.org/indicator/IT.CEL.SETS.P2?most_ recent_value_desc=true (accessed on 5 June 2021).

5. Liptrott, M. Tackling the Digital Divide: The Shift from Access to Capacity. Int. J. Public Adm. Digit. Age 2016, 3, 70-84. [CrossRef]

6. Vercruysse, J.; Reid, F.; World Economic Forum. The Fourth Industrial Revolution Can Close the Digital Divide. This Is How. 2018. Available online: https:/ / www.weforum.org/agenda/2018/09/how-do-we-close-the-digital-divide-in-the-fourth-industrialrevolution/ (accessed on 31 October 2021).

7. Nguyen, M.H.; Hargittai, E.; Marler, W. Digital inequality in communication during a time of physical distancing: The case of COVID-19. Comput. Hum. Behav. 2021, 120, 106717. [CrossRef] [PubMed]

8. The 2030 Agenda for Sustainable Development. Sustainable Development Goal 4 (SDG 4). La Asamblea General Adopta la Agenda 2030 para el Desarrollo Sostenible. 2015. Available online: https://sdg4education2030.org/the-goal (accessed on 18 August 2021).

9. Assembly, G. Resolution adopted by the General Assembly on 11 September 2015. A/RES/69/315 15 September 2015, United Nations, New York. 2015. Available online: https://www.unescwa.org/sites/www.unescwa.org/files/un_resolutions/a_res_69 315_e.pdf (accessed on 21 January 2021).

10. Hernández-Ortega, J.; Álvarez-Herrero, J.-F. Gestión educativa del confinamiento por COVID-19: Percepción del docente en España. Rev. Española Educ. Comp. 2021, 38, 129-150. [CrossRef]

11. Lai, J.; Widmar, N.O. Revisiting the Digital Divide in the COVID-19 Era. Appl. Econ. Perspect. Policy 2021, 43, 458-464. [CrossRef]

12. García-Díaz, A. Construyendo escuelas resilientes: La educación flexible, la integración y la COVID-19. Rev. Española De Educ. Comp. 2021, 38, 211-227. [CrossRef]

13. Tomczyk, L.; Eliseo, M.A.; Costas, V.; Sanchez, G.; Silveira, I.F.; Barros, M.-J.; Amado-Salvatierra, H.R.; Oyelere, S.S. Digital divide in Latin america and Europe: Main characteristics in selected countries. In Proceedings of the Iberian Conference on Information Systems and Technologies, CISTI, Coimbra, Portugal, 19-22 June 2019. [CrossRef]

14. Gu, X.; Zhu, Y.; Guo, X. Meeting the "Digital Natives": Understanding the Acceptance of Technology in Classrooms. J. Educ. Technol. Soc. 2013, 16, 392-402.

15. Bahia, K.; Delaporte, A. The State of Mobile Internet Connectivity 2020. GSMA Reports. 2020, p. 61. Available online: https://www.gsma.com/mobilefordevelopment/wp-content/uploads/2019/07/GSMA-State-of-Mobile-InternetConnectivity-Report-2019.pdf (accessed on 18 August 2021).

16. Vial, G. Understanding digital transformation: A review and a research agenda. J. Strateg. Inf. Syst. 2019, 28, 118-144. [CrossRef]

17. Van Deursen, A.J.; Van Dijk, J.A. The first-level digital divide shifts from inequalities in physical access to inequalities in material access. New Media Soc. 2019, 21, 354-375. [CrossRef]

18. Dohse, D.; Lim, C.Y. "Bad Neighborhood" and Internet Adoption in Poor Countries: What is behind the Persistent Digital Gap? Growth Chang. 2017, 49, 241-262. [CrossRef]

19. Antikainen, M.; Uusitalo, T.; Kivikytö-Reponen, P. Digitalisation as an Enabler of Circular Economy. Procedia CIRP 2018, 73, 45-49. [CrossRef]

20. Ghisellini, P.; Cialani, C.; Ulgiati, S. A review on circular economy: The expected transition to a balanced interplay of environmental and economic systems. J. Clean. Prod. 2016, 114, 11-32. [CrossRef]

21. Horan, D. Enabling integrated policymaking with the sustainable development goals: An application to Ireland. Sustainability 2020, 12, 7800. [CrossRef]

22. Lopez-Sintas, J.; Lamberti, G.; Sukphan, J. The social structuring of the digital gap in a developing country. The impact of computer and internet access opportunities on internet use in Thailand. Technol. Soc. 2020, 63, 101433. [CrossRef]

23. Visvizi, A.; Lytras, M.D.; Damiani, E.; Mathkour, H. Policy making for smart cities: Innovation and social inclusive economic growth for sustainability. J. Sci. Technol. Policy Manag. 2018, 9, 126-133. [CrossRef]

24. Cantabrana, J.L.L.; Minguell, M.E.; Tedesco, J.C. Inclusion and Social Cohesion in a Digital Society. RUSC. Univ. Knowl. Soc. J. 2015, 12, 44. [CrossRef] 
25. Rodríguez-Abitia, G.; Martínez-Pérez, S.; Ramirez-Montoya, M.; Lopez-Caudana, E. Digital gap in universities and challenges for quality education: A diagnostic study in Mexico and Spain. Sustainability 2020, 12, 9069. [CrossRef]

26. Chaoub, A.; Giordani, M.; Lall, B.; Bhatia, V.; Kliks, A.; Mendes, L.; Rabie, K.; Saarnisaari, H.; Singhal, A.; Zhang, N.; et al. 6G for Bridging the Digital Divide: Wireless Connectivity to Remote Areas. IEEE Wirel. Commun. 2021, 1-9. [CrossRef]

27. Meng, G. Nonstandardization Based on Standardization. In Proceedings of the 2016 International Conference on Architectural Engineering and Civil Engineering, Shanghai, China, 9-11 December 2016. [CrossRef]

28. Dymitrowski, A.; Mielcarek, P. Business model innovation based on new technologies and its influence on a company's competitive advantage. J. Theor. Appl. Electron. Commer. Res. 2021, 16, 2110-2128. [CrossRef]

29. Akpan, I.J.; Udoh, E.A.P.; Adebisi, B. Small business awareness and adoption of state-of-the-art technologies in emerging and developing markets, and lessons from the COVID-19 pandemic. J. Small Bus. Entrep. 2020, 1-18. [CrossRef]

30. Oztemel, E.; Gursev, S. Literature review of Industry 4.0 and related technologies. J. Intell. Manuf. 2020, 31, 127-182. [CrossRef]

31. Ibarra, D.; Ganzarain, J.; Igartua, J.I. Business model innovation through Industry 4.0: A review. Procedia Manuf. 2018, 22, 4-10. [CrossRef]

32. Hermann, M.; Pentek, T.; Otto, B. Design principles for industrie 4.0 scenarios. In Proceedings of the Annual Hawaii International Conference on System Sciences, Koloa, HI, USA, 5-8 January 2016; pp. 3928-3937. [CrossRef]

33. Wang, S.; Wan, J.; Li, D.; Zhang, C. Implementing Smart Factory of Industrie 4.0: An Outlook. Int. J. Distrib. Sens. Netw. 2016, 12, 3159805. [CrossRef]

34. Nunes, M.; Pereira, A.C.; Alves, A.C. Smart products development approaches for Industry 4.0. Procedia Manuf. 2017, 13, 1215-1222. [CrossRef]

35. Nye, B.D. ITS and the digital divide: Trends, challenges, and opportunities. In Lecture Notes in Computer Science (including subseries Lecture Notes in Artificial Intelligence and Lecture Notes in Bioinformatics); Springer: Berlin/Heidelberg, Germany, 2013 ; Volume 7926. [CrossRef]

36. Wang, C.H.; McLee, Y.; Kuo, J.H. Ten Years of Digital Divide Studies: Themes, concepts and relationships. In International Conference on Social Science and Humanity; IACSIT Press: Singapore, 2011; Volume 5.

37. Wang, C.-H.; McLee, Y.; Kuo, J.-H. Mapping the Intellectual Structure of Digital Divide. Int. J. Soc. Sci. Humanit. $2011,1,49$. [CrossRef]

38. Fang, M.L.; Canham, S.L.; Battersby, L.; Sixsmith, J.; Wada, M.; Sixsmith, A. Exploring Privilege in the Digital Divide: Implications for Theory, Policy, and Practice. Gerontologist 2018, 59, e1-e15. [CrossRef]

39. Ghermandi, A.; Sinclair, M. Passive crowdsourcing of social media in environmental research: A systematic map. Glob. Environ. Chang. 2019, 55, 36-47. [CrossRef]

40. Livingstone, S.; Helsper, E.J. Gradations in digital inclusion: Children, young people and the digital divide. New Media Soc. 2007, 9, 671-696. [CrossRef]

41. Baldassarre, M.T.; Caivano, D.; DiMauro, G.; Gentile, E.; Visaggio, G. Cloud Computing for Education: A Systematic Mapping Study. IEEE Trans. Educ. 2018, 61, 234-244. [CrossRef]

42. Acharya, B.B. Conceptual evolution of the digital divide: A systematic review of the literature over a period of five years (20102015). J. Russ. Media J. Stud. 2017, 6, 41-74. Available online: http://hdl.handle.net/10393/36756 (accessed on 18 November 2021).

43. Chesser, A.; Burke, A.; Reyes, J.; Rohrberg, T. Navigating the digital divide: A systematic review of eHealth literacy in underserved populations in the United States. Inform. Health Soc. Care 2015, 41, 1-19. [CrossRef] [PubMed]

44. Intahchomphoo, C. Indigenous peoples, social media, and the digital divide: A systematic literature review. Am. Indian Cult. Res. J. 2018, 42, 85-111. [CrossRef]

45. Yu, R.P.; Ellison, N.B.; McCammon, R.J.; Langa, K.M. Mapping the two levels of digital divide: Internet access and social network site adoption among older adults in the USA. Inf. Commun. Soc. 2016, 19, 1445-1464. [CrossRef]

46. Chavarría-Barrientos, D.; Camarinha-Matos, L.M.; Molina, A. Achieving the sensing, smart and sustainable 'Everything. Int. J. Appl. Eng. Res. 2017, 10, 575-588. [CrossRef]

47. Chavarría-Barrientos, D.; Batres, R.; Wright, P.K.; Molina, A. A methodology to create a sensing, smart and sustainable manufacturing enterprise. Int. J. Prod. Res. 2018, 56, 584-603. [CrossRef]

48. Ponce, P.; Meier, A.; Miranda, J.; Molina, A.; Peffer, T. The Next Generation of Social Products Based on Sensing, Smart and Sustainable (S3) Features: A Smart Thermostat as Case Study. IFAC-PapersOnLine 2019, 52, 2390-2395. [CrossRef]

49. Molina, A.; Ponce, P.; Miranda, J.; Cortés, D. Enabling Systems for Intelligent Manufacturing in Industry 4.0: Sensing, Smart and Sustainable Systems for the Design of S3 Products, Processes, Manufacturing Systems, and Enterprises; Springer Nature: Basingstoke, UK, 2021.

50. Boy, G.A. From rigid to flexible-From virtual to tangible an evolution of human-centered design. In Congress of the International Ergonomics Association; Springer: Cham, Switzerland, 2018; pp. 54-63. [CrossRef]

51. Longoria, I.A.-I.; Molina, A.; Bustamante-Bello, R. Smart and Connected Systems for the Non-typical User: Design Methodology to Observe the Outliers. In International Conference on Applied Human Factors and Ergonomics; Springer: Cham, Switzerland, 2021; Volume 260. [CrossRef]

52. Kitchenham, B. Procedures for performing systematic reviews. Keele Univ. UK Natl. ICT Aust. 2004, 33, 1-26. 
53. Alvarez-Icaza, I.; Molina, A.; Bustamante-Bello, R. Connected Platforms for the Non-typical User: Design Methodology to Observe the Outliers. Int. J. Comput. Commun. Eng. 2020, 9, 122-133. [CrossRef]

54. Petersen, K.; Feldt, R.; Mujtaba, S.; Mattsson, M. Systematic mapping studies in software engineering. In Proceedings of the 12th International Conference on Evaluation and Assessment in Software Engineering (EASE), Bari, Italy, 26-27 June 2008. [CrossRef]

55. García-González, A.; Ramírez-Montoya, M.-S. Systematic mapping of scientific production on open innovation (2015-2018): Opportunities for sustainable training environments. Sustainability 2019, 11, 1781. [CrossRef]

56. Velásquez-Duran, A.; Ramirez-Montoya, M.-S. Research management systems: Systematic mapping of literature (2007-2017). Int. J. Adv. Sci. Eng. Inf. Technol. 2018, 8, 44-55. [CrossRef]

57. Jabareen, Y. Building a Conceptual Framework: Philosophy, Definitions, and Procedure. Int. J. Qual. Methods 2009, 8, 49-62. [CrossRef]

58. Chen, W.; Li, X. Digital inequalities in American disadvantaged urban communities: Access, skills, and expectations for digital inclusion programs. Inf. Commun. Soc. 2021, 24, 1-18. [CrossRef]

59. Mariscal, J.; Mayne, G.; Aneja, U.; Sorgner, A. Bridging the gender digital gap. Economics 2019, 13, 1-12. [CrossRef]

60. PAHO-PanAmerican Health Organization. People over 60 have been hardest hit by COVID-19 in the Americas. News: PAHO Calls on Countries to Adapt Health Systems to Better Meet the Needs of Older Adults. 2020. Available online: https: //www.paho.org/en/news/30-9-2020-people-over-60-have-been-hardest-hit-covid-19-americas (accessed on 24 October 2020).

61. Davis, H.; Farmer, J. Including the Rural Excluded: Digital Technology and Diverse Community Participation. In Digital Participation through Social Living Labs; Chandos Publishing: Oxford, UK, 2018. [CrossRef]

62. World Health Organization. Disability and Health. Disability-A Public Health Issue. 2020. Available online: https://www.who. int/news-room/fact-sheets/detail/disability-and-health (accessed on 5 June 2021).

63. Moher, D.; Liberati, A.; Tetzlaff, J.; Altman, D.G. Preferred Reporting Items for Systematic Reviews and Meta-Analyses: The PRISMA Statement. PLOS Med. 2009, 6, e1000097. [CrossRef]

64. Harzing, A.-W.; Alakangas, S. Google Scholar, Scopus and the Web of Science: A longitudinal and cross-disciplinary comparison. Scientometrics 2016, 106, 787-804. [CrossRef]

65. Mongeon, P.; Paul-Hus, A. The journal coverage of Web of Science and Scopus: A comparative analysis. Scientometrics 2016, 106, 213-228. [CrossRef]

66. Durán Domínguez, A.; Río Rama, M.D.; Álvarez García, J. Bibliometric analysis of publications on wine tourism in the databases Scopus and WoS. Eur. Res. Manag. Bus. Econ. 2017, 23, 8-15. [CrossRef]

67. Pranckutè, R. Web of science (Wos) and scopus: The titans of bibliographic information in today's academic world. Publications 2021, 9, 12. [CrossRef]

68. Haddaway, N.R.; Bernes, C.; Jonsson, B.-G.; Hedlund, K. The benefits of systematic mapping to evidence-based environmental management. AMBIO 2016, 45, 613-620. [CrossRef]

69. Kitchenham, B.; Pretorius, R.; Budgen, D.; Brereton, O.P.; Turner, M.; Niazi, M.; Linkman, S. Systematic literature reviews in software engineering-A tertiary study. Inf. Softw. Technol. 2010, 52, 792-805. [CrossRef]

70. Bauer, M.; Gaskell, G. Classical Content Analysis: A Review. In Qualitative Researching with Text, Image and Sound; SAGE Publications Ltd.: Thousand Oaks, CA, USA, 2011. [CrossRef]

71. Ramírez-Montoya, M.-S.; Lugo-Ocando, J. Systematic review of mixed methods in the framework of educational innovation. Comunicar 2020, 28, 9-20. [CrossRef]

72. GSMA. Internet of Things. Mobile IoT Deployment Map. 2021. Available online: https://www.gsma.com/iot/deployment-map/ (accessed on 18 November 2021).

73. Kolodeznikova, I.V.; Kuznetsova, I.V.; Pronchev, G.B. Particularities of gender gap in the digital era. Astra Salvensis 2018, 6, 871-880.

74. König, R.; Seifert, A.; Doh, M. Internet use among older Europeans: An analysis based on SHARE data. Univers. Access Inf. Soc. 2018, 17, 621-633. [CrossRef]

75. Freddolino, P.P.; Lee, V.W.P.; Law, C.-K.; Ho, C. To Help and to Learn: An Exploratory Study of Peer Tutors Teaching Older Adults about Technology. J. Technol. Hum. Serv. 2010, 28, 217-239. [CrossRef]

76. Vicente, V.A.Q. An unequal decade for older people who came late to cyberspace I Una década desigual para los mayores que llegaron tarde al ciberespacio. Sociol. Probl. E Prat. 2011, 65, 51-68.

77. Hunter, E.; Travers, H.; Gibson, J.; Campion, J. Bridging the triple divide: Performance and innovative multimedia in the service of behavioural health change in remote Indigenous settings. Australas. Psychiatry 2007, 15, S44-S48. [CrossRef] [PubMed]

78. Dombrowski, L. Socially just design and engendering social change. Interactions 2017, 24, 63-65. [CrossRef]

79. Dombrowski, L.; Harmon, E.; Fox, S. Social justice-oriented interaction design: Outlining key design strategies and commitments. In Proceedings of the 2016 ACM Conference on Designing Interactive Systems: Fuse, Brisbane, Australia, 4-8 June 2016; pp. 656-671. [CrossRef]

80. Navarrete, R.; Luján-Mora, S. Bridging the accessibility gap in Open Educational Resources. Univers. Access Inf. Soc. 2018, 17, 755-774. [CrossRef]

81. Sanchez-Prieto, J.; Trujillo-Torres, J.M.; Gómez-García, M.; Gómez-García, G. The generational digital gap within dual vocational education and training teachers. Eur. J. Educ. Res. 2020, 9, 1557-1567. [CrossRef] 
82. Ayanso, A.; Cho, D.I.; Lertwachara, K. The digital divide: Global and regional ICT leaders and followers. Inf. Technol. Dev. 2010, 16, 304-319. [CrossRef]

83. Pinto, S.C.D.; Masson, D.; Villeneuve, E.; Boy, G.; Urfels, L. From requirements to prototyping: Application of human-system integration methodology to digital twin design. Proc. Des. Soc. 2021, 1, 1617-1626. [CrossRef]

84. Adler-Milstein, J. From Digitization to Digital Transformation: Policy Priorities for Closing the Gap. J. Am. Med. Assoc. 2021, 325, 717-718. [CrossRef] [PubMed]

85. Zhu, Y. Research on the human-computer interaction design in mobile phones. In Proceedings of the 2020 International Conference on Computing and Data Science, CDS 2020, Stanford, CA, USA, 1-2 August 2020; pp. 395-399. [CrossRef] 